\title{
as empresas de energia e o consumo doméstico de gás em são paulo no início do século $\mathrm{xx}^{*}$
}

\author{
João Luiz Maximo da Silva \\ Doutorando em História Social e Mestre em História Social. Faculdade de Filosofia, Letras e \\ Ciências Humanas, FFLCH, Universidade de São Paulo, USE
}

\begin{abstract}
RESUMO
Este artigo procura identificar alguns impactos produzidos no início do século XX pela introdução de tecnologias do gás no espaço doméstico. A trajetória das empresas de energia é delineada juntamente com o processo de crescimento e urbanização da cidade de São Paulo.
\end{abstract}

Palavras-chave: São Paulo, Energia a gás, Cozinha, Equipamentos domésticos, Consumo.

O objetivo deste artigo é discutir o papel das empresas de energia no fomento do consumo doméstico de gás canalizado na cidade de São Paulo no início do século XX. Como desdobramento de suas atividades nos serviços urbanos, as empresas de energia procuraram desenvolver o consumo doméstico de gás e eletricidade. Duas empresas de capital estrangeiro foram importantes neste processo, a The San Paulo Gas Company, constituída em Londres em 1869, e a The São Paulo Tramway Light and Power Company, constituída no Canadá em 1899'. Estas duas empresas, unidas mais tarde, foram as grandes responsáveis pela introdução do gás e da eletricidade em grande escala na cidade de São Paulo, a partir do final do século XIX.

\footnotetext{
* Submetido: março, 2005; aceito: maio, 2005

A companhia de eletricidade teve como primeiro nome The São Paulo Railway Light and Power Company, mudando em seguida para The São Paulo Tramway Light and Power Company para evitar confusão com a São Paulo Railway, que explorava as estradas de ferro. Usaremos o nome pelo qual a empresa passou a ser chamada pela população, Light. A esse respeito, ver SOUZA, 1989.
} 
Uma das questões que devemos considerar é o resultado do impacto provocado pelas novas empresas e seu papel em um processo mais amplo, que envolvia aspectos da urbanização levada a cabo pelo Estado. Entretanto, já existia uma transformação na mentalidade das elites, tornando possível e desejável uma série de mudanças de hábitos que fosse identificada com o progresso e o ideal urbano vigente na Europa. Assim, o "embelezamento urbano", a sanitarização e o consumo de objetos identificados com estes ideais faziam parte deste desejo de modernização. Este período trouxe uma ruptura com o passado, e a casa paulistana foi fortemente modificada neste processo de atualização, entrando em choque com antigas práticas. No espaço destas novas residências, os equipamentos domésticos a gás tiveram um papel central, pois propiciaram uma nova configuração espacial e novas relações de trabalho e convivência doméstica. Além disto, foram o ponto de ligação da casa com o espaço urbano por via das redes de distribuição de energia, um fenômeno novo na cidade de São Paulo.

A transformação de São Paulo em um centro urbano importante no comércio do café propiciou um grande volume de investimentos capitalistas que alterou radicalmente o antigo povoado. Mesmo com sua condição periférica, os centros urbanos brasileiros se desenvolveram com o processo de importação de capitais e exploração de serviços urbanos. A chegada de grupos estrangeiros como a The San Paulo Gas Co. e a Light fazia parte de um processo global de procura por novos mercados, atuando na exploração de serviços urbanos em grande escala.

O rápido crescimento da cidade no período estava fortemente associado à expansão cafeeira no oeste paulista, que transformou a capital no centro político e econômico deste movimento.Juntamente com o grande aumento da população, surgiam o crescimento e a diversificação das ati-

${ }^{2}$ Em 1897, Francisco Gualco obteve a concessão do serviço de bondes elétricos por quarenta anos e conseguiu a ampliação da concessão original para a produção e a distribuição de energia elétrica. Em 1899, um grupo articulado por Frederick Pearson fundou a The São Paulo Railway, Light and Power Company Limited, com sede em Toronto, mas com capital inglês. No mesmo ano, Gualco transferiu a concessão para o grupo Light. Em 1905, o grupo se instalou no Rio de Janeiro e, em 1912, controlava os serviços de eletricidade, bondes, gás e telefone em São Paulo, Rio de Janeiro e várias cidades do interior de São Paulo. A esse respeito, ver MENDES, 1997. 
vidades econômicas. Se num primeiro momento o café foi o principal responsável por todo este crescimento, com o tempo a cidade tornou-se um centro urbano com uma dinâmica própria. A industrialização, por exemplo, atraiu atividades urbanas correlatas, como transportes, energia, comércio, bancos, etc. Este quadro de desenvolvimento urbano foi o responsável pela atração de grandes empresas estrangeiras de exploração de energia. Os serviços de infra-estrutura urbana (transportes, comunicações e serviços urbanos) eram indispensáveis neste contexto e ofereciam oportunidades atraentes de investimento para o capital estrangeiro ${ }^{3}$.

A exploração do gás a partir do carvão exigia uma grande infra-estrutura e capital, o que era possível para uma empresa como a The San Paulo Gas Co. Devido à insuficiência da iluminação nas ruas de São Paulo, em 1863 foram contratados os empresários José Dutton e Francisco Taques Alvin, que se propunham a fornecer iluminação a gás de hidrogênio carburado. Logo em seguida, estes empresários, de comum acordo com as autoridades, transferiram seus direitos e obrigações para a The San Paulo Gas Co., empresa inglesa constituída em Londres em 1869. A concessão era para manufatura e distribuição de gás, obtido por quaisquer meios para iluminação pública e particular por 25 anos.

A empresa foi constituída em 1869 e, em 1870, foram iniciados os trabalhos de instalação dos encanamentos de gás que iriam abastecer a cidade. A autorização para funcionamento foi concedida em 28 de agosto de 1872, quando a primeira usina ficou pronta. Apoiada em um sistema de iluminação pública eficiente (em comparação com os antigos lampiões) e no contrato de monopólio na área central da cidade, a empresa pôde crescer, estendendo suas atividades para o fornecimento de iluminação particular e combustível para fins domésticos (Antecedentes 1987: 6-10).

A despeito de a The San Paulo Gas Co. estar em atividade em São Paulo desde 1872, foi apenas no início do século XX que se iniciou o fornecimento de combustível para fins domésticos (cozinha e aquecimento). Nesse período, o uso do gás estava restrito apenas à iluminação

Sobre as relações entre café, indústria e urbanização em São Paulo, ver as obras de SAES, Flávio Azevedo Marques de, A grande empresa de serviços públicos na economia cafeeira; SINGER, Paul I., Desenvolvimento econômico e evolução urbana; SILVA, Sérgio, Expansão cafeeira e expansão da indústria no Brasil; DEAN, Warren, A industrialização de São Paulo (1880-1945); CANO, Wilson, Raízes da concentração industrial em São Paulo. 
(pública e particular). Já havia experimentos com seu uso em fogões na Europa e nos Estados Unidos desde 1837, mas as primeiras aplicações foram em restaurantes e hotéis. Foi somente a partir de 1880 que cresceu lentamente o uso do gás na cozinha, com o desenvolvimento dos fogões (Giedion, 1948:538). O contrato original, assinado em 1863, dava o monopólio do fornecimento de iluminação pública e particular na cidade de São Paulo durante 25 anos. Após algumas discussões com o poder público, a companhia conseguiu, com algumas prorrogações, estabelecer o término do contrato para 1897. Mesmo com o monopólio, a empresa enfrentava uma série de dificuldades e uma das soluções encontradas foi sua extensão para o uso doméstico, que já era significativo na Europa e nos Estados Unidos. Assim, a The San Paulo Gas Co. conseguiu, com seus contatos, que o governo do Estado de São Paulo aprovasse, em 1896, a lei n. 440, que permitia a fabricação de gás para uso doméstico e industrial.

Devido aos vários problemas em relação à qualidade e à extensão da iluminação pública, havia uma grande pressão por parte da imprensa pela não renovação do contrato. Mas, por suas relações com o poder público e a ausência de um grande concorrente, a The San Paulo Gas Co. celebrou um novo contrato de concessão para iluminação pública com o governo, em 1897. A cláusula XXVII deste contrato, porém, previa a possibilidade de fornecimento de gás para outros fins. Assim, depois de preparar o terreno, em 1901 foi celebrado um termo de aditamento que regulava o fornecimento e a cobrança do gás para usos "estranhos à iluminação". No mesmo ano, a empresa inglesa passou a fornecer gás para uso doméstico e foi instalado o primeiro fogão a gás no Palácio do Governo (Souza, 1994: 73).

A emenda no contrato de 1897 regulou o suprimento e a separação de gás para outros usos (aquecimento e cozinha) a um preço menor que o praticado para iluminação. A diferença no preço, estabelecida em $20 \%$ (no mínimo), visava estimular o uso do gás dentro da casa, numa tentativa de suplantar uma atividade tradicional, o preparo dos alimentos em fogões com uso de lenha e carvão. Segundo relatório da companhia, de 1911, nos dois primeiros anos do fornecimento do combustível para cozinha, o preço chegou a ser reduzido em $33 \%$.

\footnotetext{
${ }^{4}$ Report of proceedings at the extraordinary general meeting held on friday, july 7 , 1911, The San Paulo Gas Company.
} 
A despeito de a composição do gás ser basicamente a mesma, o consumo era dividido entre iluminação pública, iluminação particular e outros fins (fogão e aquecedores). Para isto, a empresa dispunha de tubulações e medidores distintos. No início, a iluminação pública e particular consumia a maior parte do gás manufaturado pela empresa, vindo em seguida o uso como combustível para cozinha e aquecimento, que correspondia a apenas $10 \%$ do uso na iluminação particular. Esta situação se inverteu ao longo das duas primeiras décadas do século XX, fruto da estratégia adotada pela companhia e da concorrência com a eletricidade. Em 1910, o uso como combustível doméstico chegava à metade do gás usado na iluminação particular e, em 1928, atingia 89\% do consumo total de gás na cidade de São Paulo.

O grande problema era a concorrência com a Light, que melhorava cada vez mais seu sistema de iluminação e avançava sobre várias empresas das áreas de transportes, telefonia e iluminação, visando o monopólio destas atividades. Os grandes trunfos da companhia de gás eram a possibilidade de uso do gás na cozinha e, principalmente, o monopólio da iluminação pública na área central da cidade. Um encontro extraordinário da diretoria da The San Paulo Gas Co., em 1911, avaliava os problemas da companhia face à competição com a eletricidade:

Em 1899, o Conselho de Diretores entendeu que a Companhia teria que enfrentar a inevitável e severa competição de um poderoso e arrojado empreendimento elétrico, com corrente produzida em uma instalação hidrelétrica a cerca de trinta milhas. Assim como em outros lugares, também em São Paulo estava previsto que o gás estava com seus dias contados $[\ldots]^{5}$.

O contrato de monopólio e a influência política da companhia de gás sofreriam seu primeiro teste na competição com outro grupo estrangeiro, de grande poder político, técnico e econômico, o grupo Light. Mas a empresa procurava resistir, baseada em seus privilégios e no crescimento do consumo de gás para fins domésticos. Entre 1910 e 1928, a quantidade de gás para iluminação pública manteve-se praticamente inalterada em cerca de 3.000.000 de metros cúbicos anuais.

Idem. 
Neste período, em que a empresa enfrentava a competição com a eletricidade, manteve apenas sua área de contrato sem nenhuma expansão até a total desativação dos lampiões a gás, em 1936. Esta expansão era impensável, já que a eletricidade se desenvolveu rapidamente, de forma a tornar as lâmpadas mais eficientes e práticas que a iluminação a gás. A eficiência da lâmpada elétrica com filamento e o aumento do preço do gás, além das inúmeras reclamações de má qualidade e restrição dos serviços, convenceu a companhia de que a iluminação a gás estava condenada. Este problema era agravado em São Paulo, já que o gás estava sujeito a aumentos atrelados ao câmbio, enquanto a eletricidade era fornecida a preço fixo na moeda do país ${ }^{6}$. Em 1911, quando os problemas da The San Paulo Gas Co. se avolumavam, um encontro especial da diretoria avaliava o consumo doméstico como a grande esperança para a empresa:

O consumo de gás para cozinha e outros fins tem um aspecto diferenciado. Um dos contratos suplementares já mencionados, feito em meados de 1901, trata exclusivamente dessa modalidade de serviço. Em 1902 o consumo de gás para cozinha e aquecimento era de 249.300 metros cúbicos, e em 1910 alcançou 2.478.000 metros cúbicos ou um aumento de $1.000 \%$ em nove anos. Isto mostra, acionistas, o que estamos fazendo em relação ao gás para cozinha. É importante ressaltar que hoje temos mais gás fornecido para cozinha que o total para iluminação pública ou lâmpadas da cidade (...) Creio que temos um vasto campo para operações e asseguro, senhores, que isso não é fruto de minha imaginação, mas simplesmente uma avaliação baseada em fatos, quando prevejo para a Companhia no futuro um maior desenvolvimento deste ramo de negócios do que experimentamos no passado?.

Os números expressivos referentes ao consumo doméstico também indicavam um grande decréscimo da iluminação a gás. Em sua exposição aos acionistas, o presidente da reunião usa de sua eloqüência para assegurar as possibilidades de sucesso, que não seriam fruto de sua imaginação, mas baseadas nos números que revelavam o aumento do consumo de

\footnotetext{
"History of plant and growth of the services, The San Paulo Gas Company, 1949.

Report of proceedings at the extraordinary general meeting held on friday july 7, 1911, The San Paulo Gas Company.
} 
gás para fins domésticos. O tom otimista do relatório escondia as dificuldades enfrentadas na concorrência com o grupo Light. Mas o aumento do consumo de gás combustível era inquestionável, e a concessão do monopólio parecia ser mais interessante. Toda esta confiança não impediu que a empresa de gás perdesse a competição com a Light. Mesmo com a renovação de seus privilégios, a The San Paulo Gas Co. foi impedida de transferir total ou parcialmente sua concessão, e também de adquirir qualquer outra empresa para explorar a iluminação pública sem a aprovação do governo. A despeito do crescimento do gás para cozinha, a empresa estava com os dias contados, pois não poderia fazer frente à concorrência com a eletricidade. Relatório interno da empresa, em 1949, analisava os problemas que resultaram na venda do controle acionário da companhia de gás, em 1912: "Certamente a Companhia de Gás, com seus próprios recursos, não poderia cumprir suas obrigações durante o período que se estendeu de 1917 a 1922, quando uma perda acumulada de $£ 506.966$ foi registrada"s.

Mesmo com o privilégio do monopólio, a empresa necessitava cada vez mais de recursos para a modernização de seus equipamentos e para a expansão de sua rede. Em 1912, a Light adquiriu o controle acionário da The San Paulo Gas Co., com a emissão de bônus da The São Paulo Electric Company, uma de suas subsidiárias. A situação da companhia de gás não parecia um empecilho. Sua compra pela Light era considerada essencial, mesmo a um alto preço, como ressalta o mesmo relatório:

O custo registrado da aquisição do controle foi alto, $£$ 650.115-1-5 (nunca incluído nos livros da The San Paulo Gas Company). Evidentemente o perigo da compra da Companhia de Gás por outra companhia elétrica, interessada em operar em São Paulo, justificava o preço. O contrato da Companhia de Gás possibilitaria ao concorrente usufruir do direito de preferência para iluminação pública por eletricidade?

O interesse maior era o contrato da companhia de gás. A compra por outra empresa do setor elétrico poderia ser desastrosa para os planos do grupo. A aquisição da companhia de gás pela Light seguia o princípio

\footnotetext{
' The 'Comunity of interests clause' and the purchase of control by Brazilian Traction Co., may, 7, 1949.

Idem.
} 
adotado pela empresa desde o início de sua operação em São Paulo. O objetivo era o controle total de várias empresas de serviços urbanos. Com a compra do controle acionário em 1912, começou uma reestruturação da empresa, que iria modificar sensivelmente a comercialização de gás para uso doméstico, considerado o principal alvo,já que a iluminação cederia espaço para a eletricidade. Mesmo integrando o grupo Light, as atividades eram separadas e a companhia de gás continuava a fazer valer seu contrato de concessão da iluminação nas áreas centrais, mesmo que investisse cada vez mais no consumo doméstico.

O grupo Light já. tinha adquirido o controle acionário da companhia de gás do Rio de Janeiro, a Société Anonyme du Gaz, em 1905, passando a investir mais no consumo para fins domésticos. Além da modernização dos equipamentos e das tubulações, iniciou-se, em 1912, uma reestruturação do departamento comercial das companhias de gás do Rio de Janeiro e de São Paulo, com as decisões referentes à comercialização sendo feitas em conjunto.

De 1910 até 1914, o consumo de gás cresceu, devido aos melhores preços, ao grande crescimento da cidade e, principalmente, com uma propaganda intensiva iniciada em 1913 e reforçada no ano seguinte. O ritmo de crescimento só não foi maior devido ao início da Primeira Guerra Mundial, que dificultou a importação de carvão. Se em 1910 o gás combustível (cozinha e aquecimento) respondia por cerca de $25 \%$ do consumo total, em 1914 (auge da campanha publicitária) era responsável por cerca de $50 \%$.

Além do aumento dos custos do serviço, a diminuição do poder calorífico e as mudanças na composição do combustível, permitidas pelo governo, provocaram a necessidade de ajustes nos fogões e geraram reclamações dos consumidores e ataques da imprensa. Com a queda do câmbio, o preço do gás subiu, reduzindo o aumento do número de consumidores entre 1921 e 1923, a despeito da propaganda. A Revolução de 1924 paralisou por um tempo curto o aumento do consumo. Mas, em 1928, o gás para cozinha e aquecimento respondia por cerca de $89 \%$ do consumo, confirmando as previsões e as estratégias da companhia.

Mesmo mantendo autonomia jurídica, a The San Paulo Gas Co. e a Light, como integrantes do mesmo grupo, não entraram em concorrência, seguindo caminhos diferentes no tocante aos investimentos. Ao contrário da companhia de gás, a Light investia mais pesadamente no uso da eletricidade para fins de iluminação (doméstica e pública). 
O grupo Light tinha o objetivo de estabelecer várias redes interrelacionadas. Se o gás estava quase que todo restrito ao uso doméstico, a eletricidade teria uma maior diversificação. Os vários usos para a eletricidade já estavam em desenvolvimento na Europa e nos Estados Unidos, e a Light tinha como meta a exploração plena de suas possibilidades com o estabelecimento do monopólio. Com a construção da Usina de Parnaíba em 1901, viabilizou-se o fornecimento de energia elétrica para outros fins, em especial para uso doméstico em iluminação e para aparelhos em geral. Consolidava-se também o aproveitamento hidráulico para a produção de eletricidade.

Existem poucas referências ao uso do fogão elétrico na casa paulistana nesse período e mesmo posteriormente. Em países centrais, o processo de passagem do gás para a eletricidade ocorreu devido à concorrência entre as empresas distribuidoras, que competiam nos mesmos segmentos (doméstico, público e industrial). Nos Estados Unidos, este processo foi responsável por uma série de inovações tecnológicas e acréscimo de pequenos acessórios nos fogões. Segundo Jane Busch (1983: 224), os fogões elétricos começaram a ser produzidos nos Estados Unidos no início do século XX, mas a competição com o gás se acirrou na década de 30 .

A concorrência era fomentada por associações dos fabricantes e empresas de energia, como a AGA (American Gas Association) e a NELA (National Electric Light Association).Além da inovação tecnológica, a propaganda era a grande arma desta competição. Em São Paulo e no Rio de Janeiro, isto nunca aconteceu, em grande parte devido ao processo de formação do grupo Light, que acabou por concentrar o monopólio da produção e da distribuição de gás e eletricidade (além de outros serviços). Assim, o fogão a gás tornou-se o principal produto da companhia de gás, sem grande ameaça do fogão elétrico.

\section{Relações com outras fontes de energia}

Por um longo período, o principal combustível na cozinha paulista foi a lenha, e continuou sendo, mesmo com a introdução do gás e de outros combustíveis. Os fogões (de pedra, barro, ferro ou alvenaria) eram todos movidos a lenha, cortada e trazida dos arredores da cidade de São Paulo. O crescimento da cidade começou a tornar escassa a 
lenha nas imediações, como apontava Henrique Raffard em suas observações sobre a cidade de São Paulo em fins do século XIX:

Cabe aqui dizer que a lenha, que outrora vinha de Santo Amaro e outros lugares circunvizinhos da Paulicéia, onde se vendia pelo preço de $4 \$$ cada carrada, hoje é trazida em grande parte pelas vias férreas, regulando o seu preço $2 \$ 500$ ou $5 \$$ quando rachada e cortada em pequenos pedaços uniformes, existindo empresas montadas para esse fim, as quais trabalham com serras movidas a vapor (Raffard, 1977: 105).

A fácil obtenção da lenha, principalmente para as classes mais baixas, era característica de um pequeno povoado como a São Paulo de até meados do século XIX. Mas o crescimento vertiginoso da cidade diminuía a oferta de lenha, seja pela procura, seja pela diminuição das áreas de floresta. O historiador Warren Dean chama a atenção para a importância do consumo da lenha e do carvão vegetal na economia paulista no século XIX. Apesar de algumas indústrias continuarem utilizando a madeira como fonte de energia, o consumo doméstico era mais importante. A lenha era considerada a mercadoria de maior porte no abastecimento da cidade antes da industrialização, tanto que o governo de São Paulo proibiu, em 1901, o imposto sobre lenha, aplicado em alguns municípios, alegando que qualquer imposição teria o efeito de aumentar o custo de vida nas cidades (Dean, 1993:45). Assim, este produto tornou-se um negócio como outro qualquer, e passou a enfrentar a concorrência com outros tipos de combustível. A The San Paulo Gas Co. no início de suas atividades já percebia os limites do uso da lenha como combustível, ressaltado em relatório da diretoria de 1911:

Acredito que temos aqui um vasto campo para operações (...) Para isto, é suficiente entender as condições de vida em São Paulo, onde se cozinha com lenha, que está se tornando escassa devido ao desmatamento nos arredores da cidade, para prever o inevitável e constante crescimento na substituição da lenha pelo gás nas cozinhas da cidade de São Paulo ${ }^{10}$.

${ }^{10}$ Report of proceedings at the Extraordinary General Meeting, held on friday, july 7, 1911, The San Paulo Gas Company Ltd.

82 I João Luiz Maximo da Silva 
Esta avaliação continha uma grande dose de esperança da companhia no crescimento do uso do gás. Mas devemos lembrar que a reunião que deu origem a este relatório foi realizada às vésperas da compra da The San Paulo Gas Co. pelo grupo Light e se tratava de uma prestação de contas aos acionistas. A avaliação era realista, mas a diminuição do uso da lenha em prol do gás foi lenta, e estes combustíveis conviveram por um longo tempo. A diferença é que a lenha já não podia mais ser obtida tão facilmente e enfrentava vários concorrentes.

A comercialização de vários combustíveis disponíveis foi aproveitada também pela companhia de gás. A produção do gás a partir da queima do carvão mineral proporcionava alguns subprodutos no decorrer do processo. O carvão era introduzido em fornalhas, onde a temperatura chegava a cerca de 900 graus centígrados. A parte volátil deste processo se compunha do gás e do alcatrão, que eram separados para garantir a qualidade do combustível enviado para o gasômetro. O coque era o restante sólido do processo de queima do carvão, e tinha três tipos de utilização: alimentar as fornalhas, produzir gás de água carburado (um gás de qualidade inferior, utilizado para misturar ao restante e regular o estoque) e venda para consumidores como combustível para os fogões, concorrendo com o carvão vegetal (Artigas, 1980: 17).

Mesmo com toda a variedade de combustíveis usados na cozinha, os grandes concorrentes do gás eram a lenha e o carvão vegetal. Segundo Carlos Lemos (1999: 212), a partir de meados do século XIX a casa paulistana (dos segmentos mais abastados), começou a conhecer os novos fogões de ferro (importados dos Estados Unidos e Inglaterra), chamados de "econômicos", porque aqueciam com menos lenha ou carvão.

\section{Divulgação}

Havia vários problemas na entrada das novas formas de energia e dos aparelhos no espaço doméstico. Além da questão econômica, já que se tratava de uma tecnologia nova e certamente cara, havia também a resistência das donas de casa e das cozinheiras. Apresentava-se uma clara tensão entre tradição e novidade, e um dos instrumentos usados para quebrar as resistências foi a publicidade. As empresas de gás e eletricidade nos Estados Unidos, estruturadas em fortes associações e num processo de concorrência, usaram exaustivamente a publicidade e outras 
formas de promoção de seus produtos. Segundo Jane Busch (1983: 222), os fogões tinham de ser vendidos para um público desinformado e desinteressado e eram necessárias técnicas promocionais e campanha publicitária para enfatizar os valores desejados.

A propaganda tinha a tarefa não apenas de divulgar uma novidade, mas também de associar valores às novas formas de energia e seus equipamentos em contraposição a seus concorrentes. Para Ruth Cowan (1979: 223) as propagandas, nas primeiras décadas do século XX, agiam como "ideólogos", encorajando mudanças sociais. Num mercado em rápida expansão e altamente competitivo como o dos Estados Unidos, havia a necessidade não apenas da propaganda, mas de outras formas de promoção. Além da divulgação e da associação do produto com determinados valores, surgiu a necessidade de educar as donas de casa no uso dos novos equipamentos. Em 1917, o Public Service Electric and Gas Company, de New Jersey, contratou uma home economist para desenvolver um programa de educação das donas de casa sobre os benefícios do gás e da eletricidade (Goldstein, 1997: 123).

Devido à lenta difusão dos aparelhos elétricos, havia a necessidade de divulgação por meio de propagandas, exposições e show-rooms com cozinhas montadas para demonstrar o funcionamento. A existência de um departamento e uma função específica, a da home economist, comprovam a articulação de várias estratégias, no sentido de promover o uso do gás e da eletricidade. Os esforços deste departamento ajudaram a introduzir novas formas de organização do trabalho doméstico e, principalmente, de novos métodos de cozinhar e mudanças nos padrões de nutrição. A home economist aparecia como a mediadora entre a nova tecnologia e seu público-alvo, as donas de casa. Todo este esforço estava voltado para a mulher, reforçando o trabalho doméstico como atividade feminina e construindo a consumidora (Goldstein, 1997: 142). Na organização das empresas de gás no Brasil, não havia esta função, mas, ao longo da década de 1920, foi criado um departamento de economia doméstica que se propunha a divulgar supostas vantagens econômicas do uso do gás. Mas a divulgação do uso do gás estava a cargo dos departamentos comerciais das empresas carioca e paulista.

O desenvolvimento da publicidade, desde os primeiros anúncios, meramente descritivos, até as campanhas elaboradas por empresas publicitárias, estava fortemente associado ao desenvolvimento urbano e 
econômico. As empresas fornecedoras de gás e eletricidade usaram a propaganda como forma de quebrar as resistências da população e ao mesmo tempo esclarecer o funcionamento, tornando a nova tecnologia menos estranha.

Há uma grande diferença entre o padrão americano e as experiências brasileiras em relação à publicidade. No caso americano, a despeito da necessidade de divulgar e tornar conhecidas novidades como o gás e a eletricidade, era a forte competição que dava o tom das campanhas publicitárias. A publicidade era parte de um empreendimento maior, que envolvia uma série de atividades voltadas para a difusão de novas tecnologias domésticas. As vendas por catálogos tiveram também uma grande importância no crescimento do consumo em um país de grandes dimensões como os Estados Unidos.

O Brasil, mesmo em seus centros urbanos, não tinha esta dimensão de consumo, e os padrões de propagandas importados dos Estados Unidos muitas vezes destoavam da realidade. Empresas monopolistas como o grupo Light não usavam a publicidade como forma de vencer a concorrência, mas sim para divulgar e vencer as resistências às novidades, como a eletricidade e o gás. Uma das estratégias utilizadas era estigmatizar os concorrentes (a lenha e o carvão) e fixar valores novos ao uso da tecnologia. Em São Paulo e no Rio de Janeiro, já havia vários anúncios de fogões desde o final do século XIX, principalmente os fogões de ferro a lenha, importados dos Estados Unidos. Mas foi com a oferta de gás e eletricidade por uma empresa altamente organizada e formada por capital estrangeiro, como o grupo Light, que a propaganda foi usada de forma sistemática.

Os jornais sempre tiveram um papel de destaque na divulgação de produtos em pequenos anúncios, mas foram as revistas periódicas que se tornaram o principal suporte da atividade publicitária na virada do século XIX para o XX. Em São Paulo, nas primeiras décadas do século $\mathrm{XX}$, houve o surgimento de um grande número de revistas, muitas delas de vida efêmera, mas que tiveram grande destaque. Com a grande diversificação industrial e comercial da cidade, muitos comerciantes e fabricantes começam a editar folhas de reclame ou publicações para uso próprio, como o Jornal do Annuncio (1901), O Intervallo (1905), O Binóculo (1905) e A Propaganda (1906). O estabelecimento de um mercado publicitário propiciou o desenvolvimento de revistas voltadas pa- 
ra uma parcela maior da população, sustentadas em grande parte pelos anunciantes. Entre as revistas, destacam-se a Vida Moderna (1907), A Cigarra (1914) e a Revista feminina (1915), além dos almanaques e dos jornais. As revistas (e seus anúncios) eram parte integrante e legitimavam o intenso processo de transformações urbanas, vividas por cidades como São Paulo e Rio de Janeiro. Conforme Márcia Lotito, em seu estudo sobre o papel da publicidade na cidade de São Paulo, "A exaltação do progresso com a exacerbação do crescimento da cidade e omissão do conflito tal como era representado nos anúncios, constitui uma das características importantes do discurso publicitário, preocupado com a formação de um mercado consumidor" (Lotito, 1997: 81).

Essa preocupação com a formação de um mercado consumidor era ainda mais importante no caso do gás e da eletricidade, fomentando o consumo de um tipo de energia e aparelhos em substituição à antiga tradição enraizada na cozinha brasileira. E fica clara já no início do fornecimento de gás para uso doméstico, como vemos em relatórios da The San Paulo Gas Co. em 1903: "O gerente, em recente carta, afirma que as pessoas das classes mais baixas estão começando a usar gás. A companhia está tomando medidas para ensinar as pessoas a usar o gás para cozinha e aquecimento, e até agora os resultados são satisfatórios"11.

Uma das preocupações era com o manuseio dos equipamentos. As propagandas muitas vezes se constituíam em verdadeiras bulas, esclarecendo vários aspectos em relação ao funcionamento, principalmente no caso do fogão a gás, mas isto não parecia suficiente, e seria necessária a adoção de outras ações, voltadas para a educação e não apenas de apresentação do produto. Vários problemas tornaram lenta a adoção do gás doméstico em São Paulo. A resistência à novidade e o alto preço aumentavam as dificuldades, como constatava a companhia:

A novidade do produto como combustível, o custo comparativamente alto do gás, devido a baixa taxa do câmbio durante os primeiros anos da guerra, o baixo preço de outros combustíveis, a facilidade em se conseguir empregados acostumados aos fogões a lenha, e a timidez da companhia em estimular o produto foram responsáveis pelo lento progresso feito no início. De 1910 até o início da

Meetings of Companies and directors report, The San Paulo Gas Company Ltd., 1903. 
guerra mundial, com melhores preços do gás e o evidente crescimento de São Paulo, o gás combustível teve um rápido progresso. A propaganda que começou em 1913 e foi intensificada em junho de 1914 produziu excelentes resultados ${ }^{12}$.

Entre os problemas que teriam dificultado a expansão do uso do fogão a gás, o relatório destaca os custos e o fato de ser algo novo. Resolver o problema do preço era uma questão administrativa, mas divulgar uma novidade exigia publicidade. Uma das soluções seria esta intensa campanha publicitária, que se iniciou em 1913, apesar de propagandas esparsas anteriormente publicadas em revistas e jornais. $O$ principal objetivo da companhia de gás era convencer o consumidor a se conectar à rede. Isto implicava obter o fogão (ou aquecedor) e todo o aparato de abastecimento (tubulações e medidores). Uma vez conectado, o fornecimento era ininterrupto e a empresa se encarregava de incentivar o consumo de gás, oferecendo descontos a partir de um patamar mínimo. Estabelecia-se, assim, uma nova relação no consumo, completamente dissociada de necessidades específicas. A relação de consumo, assim como outras formas de relacionamento com a empresa (contrato, manutenção, inspeção, etc), apresentava-se de forma indireta e abstrata. Tudo isto implicava novas formas de mediação de antigas práticas domésticas, a partir de então submetidas a novas regras. Isto acabaria trazendo dificuldades no relacionamento com uma empresa internacional, mas ficava obscurecido pelo discurso da propaganda, sempre ressaltando os possíveis ganhos obtidos na adesão a um novo sistema.

A experiência da Société Anonyme du Gaz ajudou a The San Paulo Gas Co., quando ambas as empresas passaram a fazer parte do grupo Light. Em São Paulo, a campanha publicitária começou em 1912 e foi intensificada em 1914, principalmente nos jornais. Além das propagandas em jornais e revistas, a empresa passou a distribuir folhetos nas ruas e manter show-room com exibição de fogões e outros equipamentos. A companhia de gás também abriu lojas onde mantinha um corpo de vendedores e propagandistas, que ganhavam comissão pela venda de fogões. Uma série de correspondências entre George Seylaz (superin-

\footnotetext{
${ }^{12}$ History of plant and growth of the services, The San Paulo Gas Company Ltd., s.d.
} 
tendente do departamento comercial em São Paulo) e H. B. Harrop (gerente do Rio de Janeiro) ${ }^{13}$ mostra a importância da reorganização do departamento comercial e como ela privilegiou atividades ligadas à divulgação dos fogões a gás. Foi criado todo um corpo especializado para a venda e a divulgação do gás e de equipamentos domésticos, sempre em consonância com o Rio de Janeiro. Havia uma série de novos procedimentos referentes a informes de vendas e relatórios com orçamentos de instalações, que caracterizavam a existência de uma grande estrutura voltada para a venda e a manutenção dos aparelhos.

Ao contrário das propagandas de aparelhos domésticos que se limitavam a informar os objetos à venda e o nome da loja, a campanha das empresas de gás visava apresentar um novo produto, associando-o a determinados valores em contraposição ao uso da lenha e do carvão e, mais importante, fixar o produto: "fogão a gás", sempre presente com destaque. As atividades do departamento comercial envolviam também a distribuição de folhetos nas ruas, visando divulgar e popularizar seu principal produto. Em carta de 19 de agosto de 1914, o superintendente do departamento comercial da The San Paulo Gas Co. informava ao escritório do Rio de Janeiro sobre a distribuição:

Recebemos ontem a noite seu telegrama dando instruções para a distribuição de folhetos. As provas ficaram prontas nesta manhã e 200 folhetos foram distribuídos a tarde. Enviei especialmente para este trabalho funcionários que trabalham na manutenção da iluminação particular. Você encontrará em anexo um exemplar do folheto que distribuímos ${ }^{14}$.

Funcionários de outras áreas eram deslocados para este trabalho. Tratava-se de uma campanha agressiva que muitas vezes se chocava com as autoridades públicas, ferindo a lei de posturas municipais. A novidade não era apenas do produto, mas também das formas de divulgação, o que causava problemas em São Paulo. Em carta de 27 de agosto de 1914, George Seylaz informava o Rio de Janeiro sobre a situação: "Experimentamos algumas dificuldades com a distribuição de folhetos. Existe

Correspondências. Fundo George Seylaz, FPHESP.

Idem. 
uma postura municipal proibindo a distribuição de folhetos soltos e alguns de nossos homens têm sido perseguidos por conta disso." Os funcionários não tinham nenhum respaldo na atividade de distribuição dos folhetos, fugindo das autoridades por absoluta falta de informações sobre a legalidade dos procedimentos. Na resposta do Rio de Janeiro, em 28 de agosto de 1914, a solução:

Considerando a postura municipal que proíbe a distribuição de folhetos soltos, acho que o contrato de gás em São Paulo exige que a Companhia imprima e distribua determinadas informações como fazemos no Rio. Se assim for, devemos imprimi-las no verso futuros folhetos e a polícia não poderá interferir ${ }^{15}$.

Fica claro que, no Rio de Janeiro, este tipo de atividade ligado à divulgação era algo mais corriqueiro, ao contrário de São Paulo. Mas a adoção do gás envolvia não apenas a divulgação de suas qualidades, mas o aprendizado do uso de uma nova forma de energia pouco conhecida e o uso de um aparelho altamente especializado e totalmente mecanizado. Apesar de todo este aparato, a divulgação feita pelo grupo Light não tinha o mesmo grau de desenvolvimento da indústria americana. Além das óbvias diferenças entre as indústrias e os mercados consumidores brasileiro e americano, fica claro que um dos diferenciais é o fato de não haver concorrência. Nos Estados Unidos, a forte concorrência entre a indústria do gás e da eletricidade provocou não só o desenvolvimento da publicidade e da educação doméstica, mas a inovação tecnológica (Goldstein, 1983, Busch, 1997). Segundo Jane Busch (1983: 223), com o desenvolvimento técnico do fogão elétrico a partir de 1930, as indústrias enfrentaram o problema de aumentar a demanda de consumo para estes aparelhos. Além das estratégias de marketing, a competição levou ao maior desenvolvimento do desenho industrial em série e, em última instância, à obsolescência programada (Goldstein, 1997: 147). No nosso caso, com o monopólio do gás e da eletricidade pela Light, no Rio de Janeiro e em São Paulo, esta competição não aconteceu. O maior competidor do fogão a gás nunca foi o fogão elétrico, mas a lenha e o carvão. Para vencer a resistên-

Idem. 
cia da dona de casa, era necessário combater a antiga tradição da cozinha brasileira, impondo a mecanização da área de serviço. Para isto identificavam-se o gás e a eletricidade com as transformações em curso nas principais cidades brasileiras, desprestigiando a antiga cozinha e também a experiência das antigas cozinheiras.

O fato é que a lentidão na adoção do gás na cozinha estava ligada não somente a fatores econômicos, mas sobretudo às resistências em relação à operação dos novos equipamentos domésticos. As noções de progresso que as elites endossavam (e que envolviam desde requisitos sanitários até a racionalização das tarefas, sem excluir as dimensões estéticas) inseriam-se com dificuldade na ordem social vigente - principalmente nas relações de trabalho. As empresas de energia procuravam fomentar o consumo de gás e eletricidade (além dos equipamentos correspondentes) apelando para um desejo difuso de modernização das elites urbanas. Apesar do limite do consumo de gás, ele teve um grande impacto no desenvolvimento de uma nova casa (principalmente a cozinha), definindo um modelo ideal, além de seu papel na definição do espaço urbano da cidade de São Paulo. Condensou-se uma articulação de amplas conseqüências, entre Estado (agente determinante), capital (capital estrangeiro e seus interesses) e infra-estrutura (novo vetor de produção do espaço urbano e doméstico).

\section{Fontes}

Fundos arquivísticos - Fundação do Patrimônio Histórico da Energia de São Paulo Meetings of companies and director reports, San Paulo Gas Company, The Brazilian Review, august, $4^{\text {th }} 1903$.

Report of proceeâings at the extraordinary general meeting, held on friday july 7, 1911.

Fundo George E. Seylaz - correspondências e relatórios; Cartas trocadas entre George

Seylaz (São Paulo Gas Company) e H. B. Harrop (Société Anonyme du Gaz-RJ), 1914.

The 'comunity of interests clause' and the purchase of control by Brazilian Traction

Co., The San Paulo Gas Company Ltd., may $7^{\text {th }} 1949$.

History of plant and growth of the services, The San Paulo Gas Company, may 4 $4^{\text {th }} 1949$.

\section{Referências bibliográficas}

ANTECEDENTES históricos, Início da iluminação pública em São Paulo. São Paulo, Comgás, 1987. 
ARTIGAS, Rosa Camargo (org.), Casa âas Retortas, São Paulo, Secretaria Municipal de Cultura, 1980.

AS ORIGENS do gás e sua industrialização em São Paulo, São Paulo: Comgás, 1987.

BUSCH,Jane, "Cooking competition: technology on the domestic market in the 1930's", Technology and Culture, Chicago, v. 24, n. 2, abr. 1983, pp. 222-245.

COWAN, Ruth Schwartz, "The 'Industrial Revolution' in the home. Household technology and social changes in 20th-century", Technology and Culture, Chicago, n. 1, v. 17, 1979, pp.1-23.

DEAN, Warren, A industrialização de São Paulo (1880-1945), São Paulo: Difel / Edusp, 1971. "A floresta como fonte de energia na urbanização e na industrialização de São Paulo: 1900-1950", Anais do Primeiro Seminário Nacional de História e Energia, São Paulo, v. 2, 1987, pp. 41-47.

DIAS, Renato Feliciano (Coord.), Panorama do setor de energia elétrica no Brasil, Rio de Janeiro: Centro de Memória da Eletricidade no Brasil, 1988.

GIEDION, Siegfried, Mechanization takes command: a contribution to anonymous history. New York, W.W. Norton, 1948.

GOLDSTEIN, Carolyn M., "From service to sales: Home economics in Light and Power, 1920-1940", Technology and Culture, v. 38, n. 1.jan. 1997, pp. 121-152.

GRAHAM, Richard, Grã-Bretanha e o início da modernização no Brasil. São Paulo: Brasiliense, 1973.

LEMOS, Carlos, A República ensina a morar (melhor), São Paulo: Editora Hucitec, 1999.

LOLILO, Márcia Padilha, "A cidade como espetáculo: publicidade e vida urbana na São Paulo dos anos 20, São Paulo", Dissertação (Mestrado) em História Social — Faculdade de Filosofia, Letras e Ciências Humanas, Universidade de São Paulo, 1997.

MENDES, Dirce Paula et al."A formação do Grupo Light", Memória Eletropaulo, São Paulo, n. 24,1997, p. 35-61.

MENESES, Ulpiano T. Bezerra de, "O fogão da Société Anonyme du Gaz. Sugestões para uma leitura histórica de imagem publicitária", Projeto História, São Paulo, n. 21, nov. 2000, pp. 105-119.

RAFFARD, Henrique, Alguns dias na paulicéia, São Paulo: Academia Paulista de Letras, 1977.

SAES, Flávio Azevedo Marques de, "Café, indústria e eletricidade em São Paulo", História \& Energia. São Paulo, n. 1, maio de 1986, pp.21-31.

SOUZA, Edgard de, História da Light: primeiros 50 anos, São Paulo: Eletropaulo, 1989.

SZMRECSÁNYI, T; SAES, Flávio, "Energia elétrica e capital estrangeiro: o caso da São Paulo Light 1899-1904", Resgate: revista de cultura, Campinas, n. 4, 1992, pp. 9-17. 